\title{
SEX ALLOCATION IN MOUND-BUILDING ANTS: THE ROLES OF RESOURCES AND QUEEN REPLENISHMENT
}

\author{
William D. Brown, ${ }^{1,2,4}$ Laurent Keller, ${ }^{1}$ And Liselotte SundströM ${ }^{3}$ \\ ${ }^{1}$ Institute of Ecology, Bâtiment de Biologie, University of Lausanne, 1015 Lausanne, Switzerland \\ ${ }^{2}$ Department of Biology, Syracuse University, 108 College Place, Syracuse, New York 13244 USA \\ ${ }^{3}$ Department of Ecology and Systematics, Division of Population Biology, University of Helsinki, P.O. Box 17, \\ FIN-00014 Helsinki, Finland
}

\begin{abstract}
Social Hymenoptera have become key organisms for tests of sex-ratio theory. We assess the role of resources for explaining sex-ratio variation in a highly male-biased population of the ant Formica exsecta. Key predictions of two of the three leading hypotheses invoking an effect of resource availability on sex ratios in social insects are not upheld. One prediction of the multifaceted parental-investment hypothesis is that colonies with greater brood production will rear a greater proportion of their diploid offspring as reproductive females (gynes), rather than workers. This study shows the positive correlation between female-biased sex ratio and the production of brood by female-producing colonies was not the outcome of a trade-off in the production of workers vs. gynes. The main prediction of the constant-female hypothesis is that investment in gynes should be constant. We found extreme variation among colonies in the number of gynes produced. By contrast, all the predictions of the queen-replenishment hypothesis were supported. The queen-replenishment hypothesis predicts that colonies produce gynes only when queen number is so low that colony production of brood is reduced, or colony survival threatened. We found that, as predicted by this hypothesis, female-producing colonies had fewer queens and produced a lower biomass of brood than male-producing colonies. In contrast, male-producing colonies had lower production per queen, and were more likely to be limited by external resources. This suggests that queen number limits production in female-producing colonies. These data provide evidence of adaptive adjustment of resources to worker, gyne, and male brood.
\end{abstract}

Key words: ants; Formica exsecta; Formicidae; Hymenoptera; local resource competition; polygyny; reproductive allocation; resource limitation; sex ratio; social insects.

\section{INTRODUCTION}

Sex allocation in social insects provides opportunities to test inclusive fitness theory, sex-ratio theory, and parent-offspring conflict. In Hymenoptera, females are diploid, and males are haploid. As a result, sisters are more closely related to each other $(r=0.75)$ than to their brothers $(r=0.25)$, whereas reproductive females are equally related to their sons and daughters $(r=0.50)$. These asymmetries in genetic relatedness cause colony members to differ in inclusive fitness interests. Queens are expected to favor an equal investment in the sexes, but workers are expected to adjust sex ratios depending on the ratio of their relatedness to female vs. male brood. This leads to queen-worker conflict over relative allocation of resources in the two sexes (Trivers and Hare 1976, Charnov 1978, Nonacs 1986a, Pamilo 1991).

Based on this theory, the population sex allocation, defined as the energy investment in females vs. males,

Manuscript received 7 March 2001; revised 18 September 2001; accepted 24 September 2001.

${ }^{4}$ Present address: Department of Biology, State University of New York, Fredonia, New York 14063 USA.

E-mail: William.Brown@fredonia.edu should be female-biased if workers control colony sex allocation. The prediction of female-biased sex allocation indeed often holds in ants, based on extensive interspecific comparative studies (Trivers and Hare 1976). Colony sex allocation might therefore be expected to have a random, unimodal distribution around a population average (see Bourke and Chan 1994). However, colony sex allocation is often bimodally distributed, with some colonies producing mainly gynes (reproductive females) and others mainly males (e.g., Pamilo and Rosengren 1983, Nonacs 1986a, Elmes 1987, Vargo and Fletcher 1987, Chan and Bourke 1994, Sundström 1994, Sundström et al. 1996). Several hypotheses have been proposed to explain specialized sex ratios in social Hymenoptera. The aim of this study is to test three hypotheses that invoke a role for resource availability. These hypotheses are described below, and their main predictions are given in Table 1.

1) The multifaceted parental-investment hypothesis holds that colonies may be limited by the amount of brood or resources available to raise the brood (Rosenheim et al. 1996). Colonies that are brood limited should produce the larger sex (in this species gynes), whereas resource-limited colonies with an abundance of egg-layers and brood should produce the sex that 
TABLE 1. Relationship between colony productivity and sex ratio, and other predictions of three hypotheses.

\begin{tabular}{|c|c|c|c|c|c|c|c|}
\hline \multirow[b]{4}{*}{ Hypotheses } & \multicolumn{7}{|c|}{ Predictions } \\
\hline & \multirow{2}{*}{\multicolumn{2}{|c|}{ Entire population }} & \multicolumn{2}{|c|}{$\begin{array}{l}\text { Between male- and female- } \\
\text { producing colonies }\end{array}$} & \multicolumn{3}{|c|}{ Within female-producing colonies } \\
\hline & & & \multirow{2}{*}{$\begin{array}{c}\text { Sex } \\
\text { specialization } \\
\text { of colonies } \\
\text { with greater } \\
\text { brood } \\
\text { production } \\
\end{array}$} & \multirow{2}{*}{$\begin{array}{c}\text { Sex } \\
\text { specialization } \\
\text { of colonies } \\
\text { with greater } \\
\text { brood } \\
\text { production } \\
\text { per queen }\end{array}$} & \multirow{2}{*}{$\begin{array}{l}\text { Sex ratio } \\
\text { with greater } \\
\text { brood } \\
\text { production }\end{array}$} & \multirow{2}{*}{$\begin{array}{l}\text { Sex ratio } \\
\text { with greater } \\
\text { brood } \\
\text { production } \\
\text { per queen }\end{array}$} & \multirow{2}{*}{$\begin{array}{l}\text { Correlation } \\
\text { between brooc } \\
\text { production } \\
\text { and proportion } \\
\text { of females } \\
\text { developing } \\
\text { as gynes }\end{array}$} \\
\hline & $\begin{array}{l}\text { Population } \\
\text { sex ratio }\end{array}$ & $\begin{array}{l}\mathrm{CV} \text { in biomass } \\
\text { of gynes } \\
\text { produced }\end{array}$ & & & & & \\
\hline $\begin{array}{l}\text { Multifaceted } \\
\text { parental in- } \\
\text { vestment } \dagger\end{array}$ & $\mathrm{NA}$ & high & females & females & female bias & female bias & positive \\
\hline $\begin{array}{l}\text { Constant-fe- } \\
\text { male§ }\end{array}$ & male bias & low & males $\|$ & males $\|$ & male bias $\|$ & male bias $\|$ & NA \\
\hline $\begin{array}{l}\text { Queen replen- } \\
\text { ishment } \mathscr{}\end{array}$ & male bias & high & males & females & $\mathrm{NA}$ & female bias & NA \\
\hline Observed & male bias & high & males\# & females & female bias & female bias & negative \\
\hline
\end{tabular}

$\dagger$ Nonacs (1986a) and Rosenheim et al. (1996).

¥ These predictions assume that females benefit more than males from larger body size.

$\S$ Frank (1987).

\| These predictions are based on production of sexual offspring (i.e., excluding workers).

II Brown and Keller (2000).

\# Male-producing colonies had greater total production but did not differ in sexual production.

requires less investment per individual (in this species males). Alteration of sex allocation is caused by differentially feeding diploid (female) offspring. When resources are scarce, diploid offspring receive less food and become workers instead of gynes, while haploid offspring still develop into reproductive males; when resources are abundant, diploid offspring receive more food and develop into gynes. As a result, sex allocation should become more female-biased when resources are abundant (Nonacs 1986a, b). Hence, a major prediction of the multifaceted parental-investment hypothesis is that there is a trade-off between the production of gynes and workers, the outcome of which will depend on resource availability.

2) The constant-female hypothesis (Frank 1987) is a model of local resource competition (Clark 1978) developed for species in which reproductive competition occurs among related individuals. In ants, queens within a single nest or a cluster of nests may compete for limited resources, such as nest sites or offspring provisioning by workers. The constant-female hypothesis assumes that the likelihood of competition among siblings is independent of the productivity of these assemblages, and predicts that colonies will produce only gynes up to a discrete threshold, and then only males if resources allow investment beyond this threshold (Frank 1987). Thus, there should be little variation among colonies in the biomass of gynes produced. Small broods are predicted to be mostly female, and large broods are predicted to be mostly male.

3) Finally, the queen-replenishment hypothesis was recently proposed to account for split-sex ratios in polygynous (multiple queens per nest) ants (Brown and Keller 2000). In polygynous ants, queens frequently remain in their mother nest after mating and eventually disperse with workers to initiate new colonies nearby (Bourke and Franks 1995, Keller 1995). This mode of reproduction may lead to intense local resource competition within colonies, and is often associated with dramatically male-biased sex ratios (reviewed in Bourke and Franks 1995, Crozier and Pamilo 1996). Brown and Keller (2000) proposed that, in such species, the production of new queens should occur preferentially, or only, in colonies that contain relatively few queens because these are the colonies that benefit most from recruiting new queens. Queen life-span is typically limited in polygynous ants (Keller and Genoud 1997), and low queen number may cause egg and brood limitation in large colonies with abundant resources (Elmes and Keller 1993). As queen numbers decrease, local resource competition between queens is reduced, and below a certain threshold there is a premium on recruiting new queens to enhance colony survival and productivity (Elmes and Keller 1993). This threshold and the value of new queens will depend on resource availability relative to the current number of queens. Thus, a major prediction of this hypothesis is that the productivity per queen should be highest in colonies producing gynes because queen number, not external resources, limits productivity in these colonies. Colonies producing gynes should also tend to have lower overall productivity than male-producing colonies because of their shortage of reproductive queens.

We tested the predictions of these three hypotheses (Table 1) in a polygynous population of Formica exsec$t a$. This population is well suited for testing hypotheses that invoke a role for resource availability because there are marked differences in sex allocation among 
colonies, and this variation is not associated with differences in relatedness asymmetry (Brown and Keller 2000).

\section{Methods}

We studied a population of $F$. exsecta located at Les Chenevières, a pasture at $\approx 1200 \mathrm{~m}$ elevation in the commune of Le Vaud in the Swiss Jura Mountains. Our method of colony selection is outlined in Brown and Keller (2000). Briefly, we chose 59 focal colonies from a population of over 300 in order to study the relationship between colony size, total production of brood, and sex allocation. Population-level sex allocation was estimated from samples taken from all colonies at the site from which we could collect sexual brood (i.e., our 59 focal colonies, plus an additional 178 colonies). Colonies in this population are known to be predominately polygynous (Cherix et al. 1980). The effective queen number was estimated using the formula $n_{\mathrm{eg}}=$ $0.75 / r_{\mathrm{f}}$, where $r_{\mathrm{f}}$ is the relatedness among nestmate females (workers and gynes) estimated per colony (Queller 1993, Ross 1993) based on allelic variation at two allozyme and two microsatellite DNA loci as discussed in Brown and Keller (2000).

\section{Colony productivity and investment ratios}

For each focal colony, we estimated the investment in males, gynes, and workers by using the mark-recapture method of Sundström (1995). The vast majority of sexuals are produced from the first eggs laid during the season. Once most larvae had entered the pupal stage, but before any had emerged as adults, nests were gently opened, and between 20 and 3980 pupae per colony were collected from just beneath the surface. A total of 63309 pupae were individually marked with a dot of ink from a nontoxic, permanent red marker (Sharpie, Sanford, Bellwood, Illinois, USA). Pupae were released back into the nest by gently opening the surface, returning the marked pupae, and closing the nest. Workers continuously move pupae within the nest (presumably to locations of optimum temperature and humidity) and effectively mix the brood. Two days later, we captured another sample of pupae, and used the proportion of marked to unmarked pupae to estimate the total number of pupae within the colony.

The ratio of workers, gynes, and males in each colony were estimated by moistening pupae in ethanol and observing the size, eye shape, and genitalia of latestage pupa. Males of $F$. exsecta are size dimorphic (Agosti and Hauschteck-Jungen 1987, Fortelius et al. 1987), and pupae fall into three nearly discrete size categories corresponding to workers, small males, and the combination of large males and gynes. Male pupae were classified as large if their size was identical to that of the gynes. Otherwise, they were counted as small males. Large males were generally produced in female-producing colonies, whereas small males were produced within both male- and female-producing colonies.

Total production of brood was estimated as the sum of the number of males, gynes, and workers times their respective dry mass. To determine dry mass, we collected adult males and gynes prior to flight as they emerged from their nest. Young workers were obtained by collecting worker pupae from each colony, and placing them in laboratory nests with $\sim 50$ adult workers and a small amount of nest material. Workers were collected within $24 \mathrm{~h}$ after eclosion from the pupae. All individuals were dried at $60^{\circ} \mathrm{C}$ for $24 \mathrm{~h}$, and weighed on a MT5 Mettler balance (Mettler-Toledo $\mathrm{GmbH}$, Greifensee, Switzerland) accurate to $0.01 \mathrm{mg}$. For a few colonies, estimates of dry mass were missing for some classes of individuals. In these colonies, we used the mean dry mass across colonies for the missing class of individuals.

We measured sex allocation as the proportion of resources invested in gynes relative to the total investment in sexual offspring. To do this, we adjusted the numerical proportion of gynes among sexual brood by their relative dry mass. We also applied the Boomsma et al. (1995) correction factor that corrects for factors such as differential fat content and respiration rate that affect the gyne-to-male cost ratio. Because this correction did not influence the outcome of our analyses, we only report results from standard dry-mass estimates of production and sex allocation.

We estimated the size of the worker force using the protocol for worker mark-recapture outlined by Sundström (1995). Before brood emerged, 200 to 2432 adult workers per colony were collected, counted, sprayed lightly with a leather and wood spray paint (Magrid, Central Islip, New York, USA), and released back onto the nest. Approximately $24 \mathrm{~h}$ later, workers were recaptured on the nest, and the total number of workers was estimated from the proportion of marked to unmarked ants. To check the accuracy of estimates of worker number, we compared these estimates with the physical size of the nests of 19 randomly selected colonies. Nest size was estimated by taking two measures of the nest diameter at right angles. The edge of the nest was defined as the limit of the area denuded of vegetation by the ants. Number of adult workers (hereafter worker number) increased significantly with average nest diameter $(r=0.52, n=19, P=0.02)$. As an additional confirmation, we completely excavated three nests (considered to be small, medium, and large) after first estimating worker number using our markrecapture methods. Nests were collected in April, when the only adult ants present were workers and old queens. We collected colonies by shoveling nest material and surrounding soil into large plastic barrels, the inside opening of which had been painted with Fluon (Whiteford $\mathrm{GmbH}$, Germany) to prevent ants from escaping. In the laboratory, we used sifters to separate ants from nest material and then aspirated 
TABLE 2. Worker number, productivity, and reproductive allocation in male- and female-producing colonies.

\begin{tabular}{lcccc}
\hline \hline & & \multicolumn{3}{c}{ Productivity biomass $(\mathrm{g})$} \\
\cline { 3 - 5 } \multicolumn{1}{c}{ Colony } & No. adult workers & Males $(95 \% \mathrm{CI} \dagger)$ & Gynes $(95 \% \mathrm{CI} \dagger)$ & $\begin{array}{c}\text { Worker brood } \\
(95 \% \mathrm{CI} \dagger)\end{array}$ \\
\hline Male-producing & $12179(8313 / 17845)$ & $14.97(8.58 / 25.60)$ & $0 \%$ & $11.97(8.08 / 19.95)$ \\
Female-producing & $15173(7631 / 20593)$ & $3.22(1.73 / 5.53)$ & $6.76(3.18 / 13.39)$ & $0.86(0.08 / 2.19)$ \\
\hline
\end{tabular}

$\dagger$ Confidence intervals are back-transformed, yielding slightly asymmetric values.

\$ By definition, gyne allocation is zero in male-producing colonies.

workers into $\sim 150$-ml plastic vials. We first determined the number of workers that filled a vial, and then determined the size of the worker forces by multiplying the total number of vials that we collected by the number of ants per vial. We also recorded the number of queens present. Mark-recapture estimates were reasonably accurate, yielding estimates of 11708 for a nest of 16110 workers, 4478 for a nest of 3339, and 395 for a nest of 249. Therefore, our methods appear to give a reasonably accurate measure of colony size.

All measures of colony size and production were normalized (Kolmogorov-Smirnov test, Lilliefors' $P>$ $0.05)$ by $\ln$ transformation prior to analyses. All proportions were transformed by the arcsine of the square root. Means were back transformed, and are reported with back-transformed $95 \%$ confidence intervals.

\section{Statistical analyses}

Our main objective was to test the relationship between sex allocation and brood production, while statistically controlling covariates such as colony size and effective queen number, when appropriate. As previously reported (Brown and Keller 2000), the population-level sex allocation was male-biased with $89.5 \%$ of the colonies producing only males. We therefore classified colonies as (1) producing males only (maleproducing colonies) or (2) producing some proportion of gynes (female-producing colonies). We first analyzed the relationship between sex-ratio class (malevs. female-producing), coded as a factorial variable and total production, incorporating colony size and effective queen number as covariates using ANCOVA. We subsequently analyzed the relationship between colony size and queen number to assess the relationship between our two covariates. Single-factor ANOVA and $t$ tests were used for additional analyses.

We next analyzed the relationship between sex allocation and brood production within female-producing colonies using regression, and followed this with bivariate analyses of total production vs. worker, gyne, and male allocation. Finally, we used regressions to analyze the relationship between effective queen number and total production.

\section{RESULTS}

All of the 59 colonies in the focal sample produced sexuals and workers. In a survey of the entire population, seven of the 250 colonies $(2.8 \%)$ produced only worker brood. Colony size, measured as the number of adult workers, did not differ significantly between male- and female-producing colonies (Table 2; $t$ test: $t=0.89, \mathrm{df}=53, P=0.38)$. Total production increased with colony size in both types of colonies (Fig. 1).

\section{Population-wide measurements}

We estimated population-level sex allocation to be $5.8 \%$ female (Brown and Keller 2000), assuming that colony-level sex allocation does not vary with total sexual production (see Results: Comparisons between male- and female-producing colonies). Such a male bias matches predictions of both the queen-replenishment and constant-female hypotheses, both of which are based on local resource competition and predict male-biased sex allocation (Table 1). However, the coefficient of variation in the total biomass of gynes produced within female-producing colonies was $169 \%$. These colonies produced between 68 and 23436 gynes

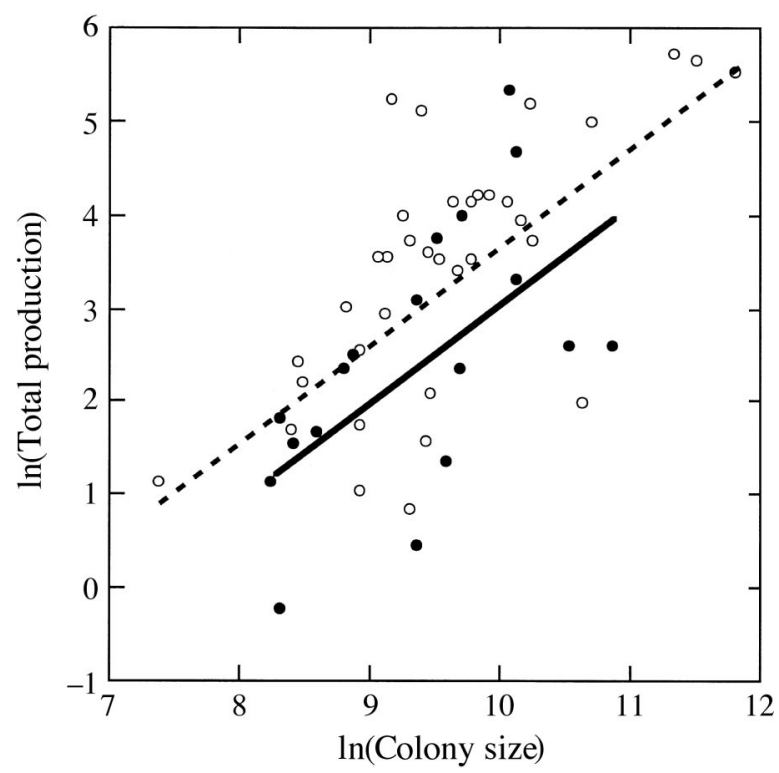

FIG. 1. Total production increases with colony size in both male- and female-producing colonies (ANCOVA: $F_{1,51}=$ 28.44, $P<0.0001$ ), but male-producing colonies had significantly greater production than female-producing colonies $\left(F_{1,51}=8.04, P=0.0065\right)$. Solid circles with solid line $=$ female-producing colonies, and open circles with dashed line $=$ male-producing colonies. Total production was originally measured in grams before log transformation. 
TABle 2. Extended.

\begin{tabular}{cccc}
\hline \hline & \multicolumn{3}{c}{ Investment ratios } \\
\cline { 2 - 4 } Sex ratio (95\% CI $\dagger)$ & Males (95\% CI $\dagger)$ & Gynes $(95 \% \mathrm{CI} \dagger)$ & $\begin{array}{c}\text { Worker brood } \\
(95 \% \mathrm{CI} \dagger)\end{array}$ \\
\hline $0 \ddagger$ & $0.52(0.42 / 0.62)$ & $0 \ddagger$ & $0.46(0.36 / 0.57)$ \\
$0.62(0.43 / 0.79)$ & $0.36(0.19 / 0.54)$ & $0.56(0.37 / 0.74)$ & $0.02(0.001 / 0.08)$ \\
\hline
\end{tabular}

(0.29-99.37 g). Such a broad range in gyne biomass is opposed to the fundamental prediction of the constant-female hypothesis that all colonies should invest the same total amount of resources in gynes (Table 1). Therefore, we exclude the constant-female hypothesis as an explanation of sex-ratio variation in the population. The coefficients of variation in worker production (female-producing colonies: $\mathrm{CV}=218 \%$; maleproducing colonies $\mathrm{CV}=245 \%$ ) and male production (female-producing colonies: $\mathrm{CV}=238 \%$; male-producing colonies $\mathrm{CV}=265 \%$ ) were also high.

\section{Comparisons between male- and female-producing colonies}

Male-producing colonies had significantly greater total production of brood than female-producing colonies (Table 2), due to a large difference in production of workers $(t=3.02$, df $=56, P=0.0038)$. We found no significant differences in sexual production between male- and female-producing colonies $(t=0.76$, df $=$ $56, P=0.45)$. Thus, the proportional investment in workers was much lower in female-producing colonies (Table 2; $t=6.48$, df $=56, P<0.0001$ ).

The effective queen number increased with colony size (ANCOVA: $F_{1,49}=8.86, P=0.0045$ ), and was higher in male-producing than in female-producing colonies of a given size $\left(F_{1,49}=8.41, P=0.0049\right)$. Total production increased with effective queen number $(r$ $=0.33, n=55, P=0.015$ ), and productivity per queen was significantly higher in female-producing than in male-producing colonies (Fig. 2), despite the lower total production of the female-producing colonies. Total production increased with effective queen number at a rate significantly lower than $b=1$ in both male-producing $(t=3.69$, df $=35, P<0.001)$ and femaleproducing colonies $(t=2.75$, df $=16, P<0.02)$. Thus, production per queen decreased as total production increased for both male- and female-producing colonies.

\section{Patterns within female-producing colonies}

The proportional investment in gynes did not change significantly with an increase in total production, whereas the proportional allocation to males decreased with increased total production (Fig. 3). As a result, colony sex allocation became more female-biased when total production increased (Fig. 4A). Sex allocation did not significantly change with colony size within female-producing colonies (Fig. 4B).

Increased colony production was associated with an increase in the proportion of brood that developed into workers (Fig. 3), and a smaller proportion of diploid brood (gynes and workers) that developed as gynes rather than workers $(r=-0.47, n=18, P=0.048)$. Finally, the proportional investment in gynes relative to all brood was not significantly correlated with effective queen number $(r=0.29, n=18, P>0.05)$ or production per queen $(r=0.10, n=18, P=0.68)$.

\section{DISCUSSION}

The population-wide sex allocation in this polygynous population of $F$. exsecta was extremely male-biased, with most colonies producing no gynes at all (Brown and Keller 2000). This strong male bias is probably due to colony budding creating local resource competition (Clark 1978, Frank 1987). The pattern of resource allocation is fully consistent with the queenreplenishment hypothesis, but inconsistent with certain predictions of the multifaceted parental-investment and constant-female hypotheses.

\section{Multifaceted parental-investment hypothesis}

Four of the six predictions of the multifaceted parental-investment hypothesis were upheld (Table 1).

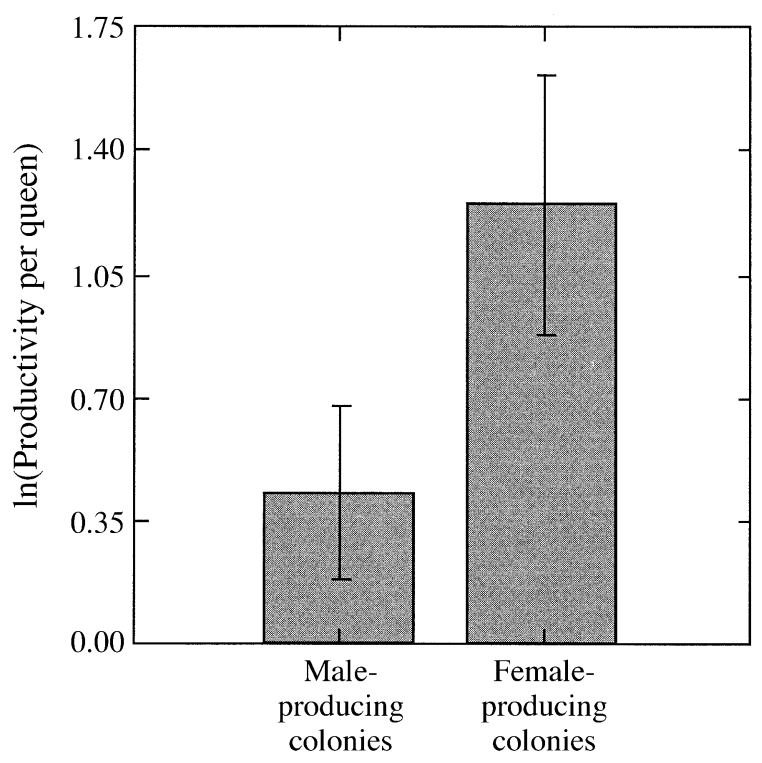

FIG. 2. The ratio of total production to effective queen number was significantly greater in female-producing colonies (Mann-Whitney $U$ test: $U=447, n=55, P=0.04$ ). Productivity per queen was originally measured in grams before $\log$ transformation. 

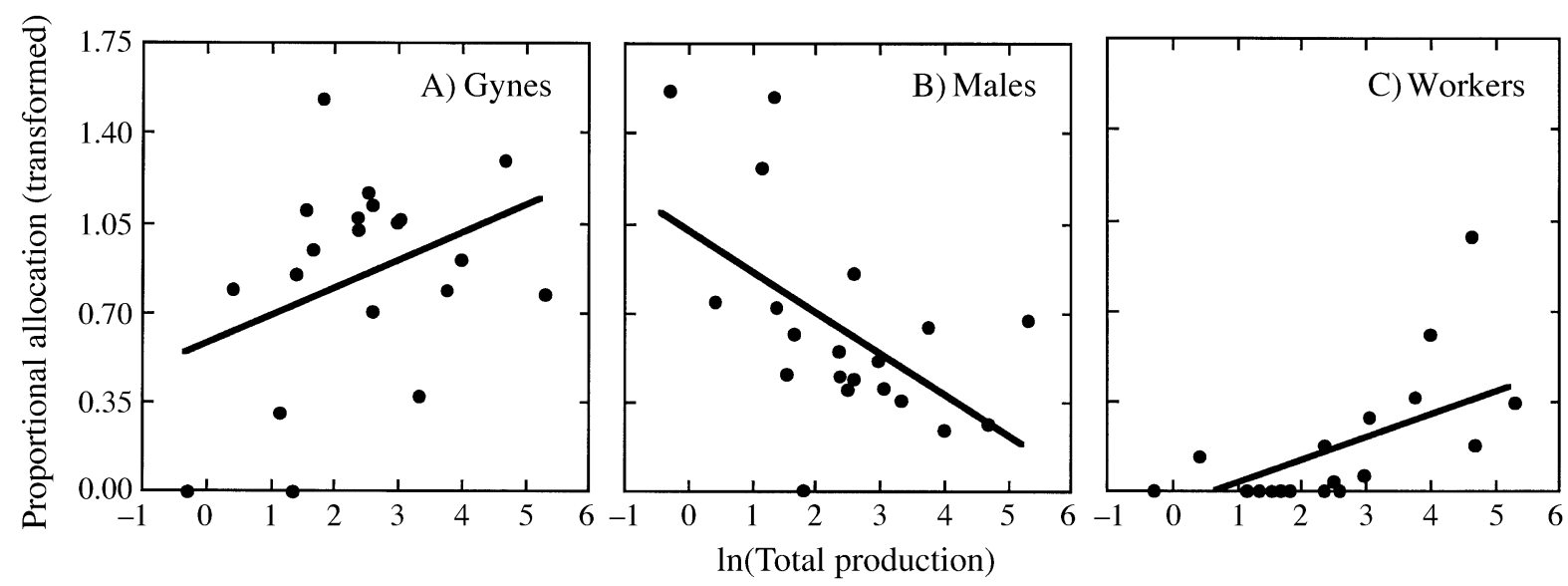

FIG. 3. (A) Within female-producing colonies, total production was not significantly correlated with proportional allocation to gynes $(r=0.37, n=20, P=0.11)$. (B) Total production was significantly negatively correlated with proportional allocation to males $(r=-0.53, n=20, P=0.016)$, and (C) significantly positively correlated with proportional allocation to workers $(r=0.45, n=20, P=0.046)$. Total production was originally measured in grams before $\log$ transformation. Ordinate scale values have been arcsine transformed.

There was a high coefficient of variation in gyne production. Between colonies, female-producing colonies had greater productivity per queen, and within colonies, sex allocation became increasingly female biased with greater total production and greater production per queen.

However, the prediction that female-producing colonies should have greater total production than maleproducing colonies was not supported. In fact, we observed the reverse pattern: Male-producing colonies were more productive than female-producing colonies. This finding could be reconciled with the multifaceted parental-investment hypothesis if males were more costly to produce than females and/or if male benefited more than gynes from larger body size. We believe this is unlikely for two reasons. First, 99\% of male-producing colonies produce only workers and small males (see Fortelius et al. 1987, Brown and Keller 2000). Thus, if male $F$. exsecta did benefit more than females from larger body size, more productive, male-producing colonies should produce larger males, which they do not (Brown and Keller 2000). Second, female-producing colonies with high productivity should produce proportionately more males, but male allocation decreased with total production in female-producing colonies.

Another key prediction of the multifaceted parentalinvestment hypothesis was also not supported. Allo-
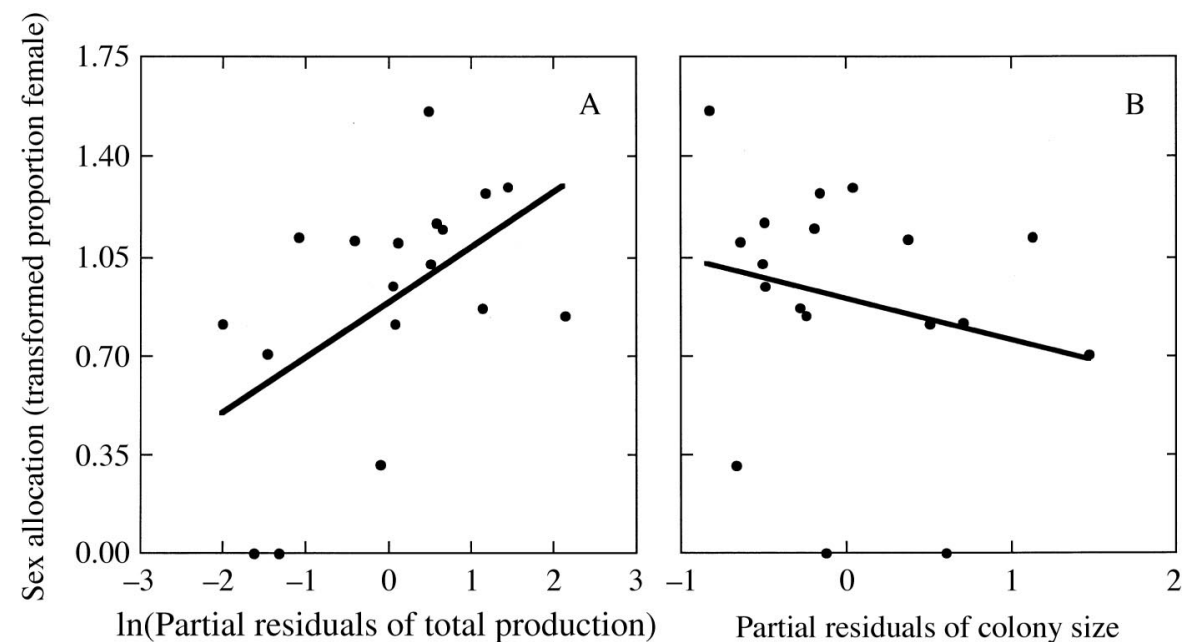

Partial residuals of colony size

FIG. 4. Sex allocation (proportion gyne biomass) increased with (A) total production $(r=0.66, n=18, P=0.028$ ), but not (B) colony size $(r=0.02, n=18, P=0.94)$ in female-producing colonies. $X$-axes are partial residuals from a multiple regression analysis of colony size, total production, and sex ratio. Total production was originally measured in grams before $\log$ transformation. Ordinate scale values have been arcsine transformed. 
cation to gyne production was not influenced by total production within female-producing colonies. Instead, allocation to workers increased, causing the proportion of diploid offspring that developed as gynes to decrease with greater total production, opposite to the pattern predicted by the hypothesis. The multifaceted parentalinvestment hypothesis thus cannot account for sex-ratio specialization in our population. However, the hypothesis may still account for size differences between individuals. For example, multifaceted parental investment predicts that offspring size will be larger when colonies are egg limited. As predicted, both workers and males were significantly larger in colonies that were more likely to be egg limited because of lower effective queen number (Brown and Keller 2000).

\section{Constant-female hypothesis}

Only two of the six predictions of the constant-female hypothesis were supported. Population sex ratio was male biased, and male-producing colonies had greater total brood production. The prediction of a constant number of females clearly is not met, as shown by the large variance in gyne production and the lack of any new gynes in $90 \%$ of the colonies. A lack of gyne production by a majority of colonies has also been reported for other polygynous populations of $F$. exsecta (Pamilo and Rosengren 1983, 1984). The constant-female hypothesis also holds that sexual production should be higher in male- than in female-producing colonies, but this was not the case. Finally, among female-producing colonies, female bias increased with both total and sexual production, opposite to the prediction of this hypothesis.

There are several reasons why the constant-female hypothesis is unlikely to explain sex-ratio variation in polygynous $F$. exsecta. Most importantly, the assumption that sibling competition is independent of colony productivity will not hold when daughters compete for reproductive opportunities within the natal colony, or if opportunities for colony budding scale with colony productivity. If the level of local resource competition varies among colonies, so should the number of offspring gynes. We found that total production per queen was higher in female-producing colonies with a smaller effective number of queens. Hence, the reproductive opportunities of daughter gynes may be greater in these colonies, and additional gynes are produced to exploit this potential.

\section{Queen-replenishment hypothesis}

All five predictions of the queen-replenishment hypothesis were supported. The key prediction that total production per queen should be greater in female-producing than in male-producing colonies was upheld. Thus, the data suggest that the number of queens limits production in female-producing colonies.

An important assumption of the queen-replenishment hypothesis is that recruitment of new queens oc- curs mostly within colonies. A genetic study of mtDNA suggests that most queens are recruited within their parental colony (Liautard and Keller 2001). There was no significant correlation between queen number and gyne production within female-producing colonies, but once the decision to produce gynes is made many additional factors in addition to the number of extant queens, such as local colony density and opportunities for founding new nests, may influence investment in females. As previously suggested (Brown and Keller 2000), colonies may produce more gynes than necessary to dilute the effects of incoming gynes from other colonies.

In conclusion, our results are most consistent with the following scenario: Local resource competition acts, over an evolutionary time scale, by selecting against gyne production in colonies with many queens, but favoring gyne production in colonies with fewer queens. The outcome is a dramatically male-biased population sex ratio. The threshold for queen replenishment depends on the resources available to the colony, with colonies that possess greater resources having a higher threshold queen number for the rearing of daughter gynes to be adopted into the nest. Multifaceted parental investment does not explain sex-ratio specialization, but may influence offspring size through greater investment in individual progeny of egg-limited colonies. These results are an important step forward in linking life-history parameters together with kinselection theory to account for reproductive strategies of social insects.

\section{ACKNOWLEDGMENTS}

We thank all our field workers, particularly Christina Chang, Michelle Kuns, and David Cuisset, for their help. Marc André Schneider helped us choose the study site, collect sexuals, and provide some body mass data. Adam Bjork, Michel Chapuisat, Else Fjerdingstad, Deborah Gordon, Peter Nonacs, Ian Robertson, Larry Wolf, and an anonymous referee provided valuable comments on the manuscript. Several Swiss NSF grants, and the Academy of Finland (LS) funded this paper.

\section{Literature Cited}

Agosti, D., and E. Hauschteck-Jungen. 1987. Polymorphism of males in Formica exsecta Nyl. (Hym. Formicidae). Insectes Sociaux 34:280-290.

Boomsma, J. J., L. Keller, and M. G. Nielsen. 1995. A comparative analysis of sex ratio investment parameters in ants. Functional Ecology 9:743-753.

Bourke, A. F. G., and G. L. Chan. 1994. Split sex ratios in ants with multiple mating. Trends in Ecology and Evolution 9:120-122.

Bourke, A. F. G., and N. R. Franks. 1995. Social evolution in ants. Princeton University Press, Princeton, New Jersey, USA.

Brown, W. D., and L. Keller. 2000. Colony sex ratios vary with queen number but not relatedness asymmetry in the ant Formica exsecta. Proceedings of the Royal Society of London B 267:1751-1757.

Chan, G. L., and A. F. G. Bourke. 1994. Split sex ratio in a multiple-queen ant population. Proceedings of the Royal Society of London B 258:261-266.

Charnov, E. L. 1978. Evolution of eusocial behavior: off- 
spring choice or parental parasitism. Journal of Theoretical Biology 75:451-465.

Cherix, D., P. Werner, and F. Catzeflis. 1980. Organisation spatiale d'un système polycalique chez Formica (Coptoformica) exsecta Nyl. (Hymenoptera: Formicidae). Mitteilungen der Schweizerischen Entomologische Gesellschaft 53:163-171.

Clark, A. B. 1978. Sex ratio and local resource competition in a prosimian primate. Science 201:163-165.

Crozier, R. H., and P. Pamilo. 1996. Evolution of social insect colonies: sex allocation and kin selection. Oxford University Press, Oxford, UK.

Elmes, G. W. 1987. Temporal variation in colony population of the ant Myrmica sulcinodis. II. Sexual production and sex ratios. Journal of Animal Ecology 56:573-583.

Elmes, G. W., and L. Keller. 1993. Distribution and ecology of queen number in ants of the genus Myrmica. Pages 294307 in L. Keller, editor. Queen number and sociality in insects. Oxford University Press, Oxford, UK.

Fortelius, W., P. Pamilo, and L. Sundström. 1987. Male size dimorphism and alternative tactics in Formica exsecta ants (Hymenoptera, Formicidae). Annales Zoologici Fennici 24: 45-54.

Frank, S. A. 1987. Variable sex ratio among colonies of ants. Behavioral Ecology and Sociobiology 20:195-201.

Keller, L. 1995. Social life: the paradox of multiple-queen societies. Trends in Ecology and Evolution 10:355-360.

Keller, L., and M. Genoud. 1997. Extraordinary lifespans in ants: a test of evolutionary theories of ageing. Nature $\mathbf{3 8 9}$ : 958-960.

Liautard, C., and L. Keller. 2001. Restricted effective queen dispersal at a microgeographic scale in polygynous populations of the ant Formica exsecta. Evolution 55:24842492.

Nonacs, P. 1986a. Ant reproductive strategies and sex allocation theory. Quarterly Review of Biology 61:1-21.
Nonacs, P. 1986b. Sex ratio determination within colonies of ants. Evolution 40:199-204.

Pamilo, P. 1991. Evolution of colony characteristics in social insects. 1. Sex allocation. American Naturalist 137:83-107.

Pamilo, P., and R. Rosengren. 1983. Sex ratio strategies in Formica ants. Oikos 40:24-35.

Pamilo, P., and R. Rosengren. 1984. Evolution of nesting strategies of ants: genetic evidence from different population types of Formica ants. Biological Journal of the Linnean Society 21:332-348.

Queller, D. C. 1993. Genetic relatedness and its components in polygynous colonies of social insects. Pages 59-83 in L. Keller, editor. Queen number and sociality in insects. Oxford University Press, Oxford, UK.

Rosenheim, J. A., P. Nonacs, and M. Mangel. 1996. Sex ratios and multifaceted parental investment. American Naturalist 148:501-535.

Ross, K. G. 1993. The breeding system of the fire ant Solenopsis invicta, and its effects on colony genetic structure. American Naturalist 141:554-576.

Sundström, L. 1994. Sex ratio bias, relatedness asymmetry and queen mating frequency in ants. Nature 367:266-268.

Sundström, L. 1995. Sex allocation and colony maintenance in monogyne and polygyne colonies of Formica truncorum (Hymenoptera: Formicidae): the impact of kinship and mating structure. American Naturalist 146:182-201.

Sundström, L., M. Chapuisat, and L. Keller. 1996. Conditional manipulation of sex ratios by ant workers: a test of kin selection theory. Science 274:993-995.

Trivers, R. L., and H. Hare. 1976. Haplodiploidy and the evolution of the social insects. Science 191:249-263.

Vargo, E. L., and D. J. C. Fletcher. 1987. Effect of queen number on the production of sexuals in natural populations of the fire ant, Solenopsis invicta. Physiological Entomology 12:109-116. 